\title{
O TRATAMENTO CORRETIVO DA FORMA NO ENSINO E NA APRENDIZAGEM DE LÍNGUA ESTRANGEIRA
}

The corrective treatment of form in the teaching and learning of a foreign language

\author{
Marília dos Santos Lima* \\ Magali de Moraes Menti
}

\section{Introdução}

$\mathrm{T}$

ratamento corretivo é aqui entendido como um evento interacional vinculado aos estudos com foco na forma num contexto predominantemente comunicativo, incluindo a probabilidade de negociação da forma na interação que ocorre na sala de segunda língua (L2) ou língua estrangeira (LE).

Spada (1997) define instrução com foco na forma (IFF) como qualquer esforço pedagógico usado para chamar a atenção dos aprendizes para uma forma lingüística de modo implícito ou explícito, o que pode ser operacionalizado através do ensino de regras lingüísticas ou de reações corretivas aos erros dos alunos. ${ }^{1}$ Assim, na literatura encontramos relatos de estudos de intervenção (Carroll and Swain, 1993; White 1998; Spada e Lightbown, 1999; Samuda, 2001, entre outros), nos quais os professores podem planejar e tratar de modo sistemático, explicitamente ou não, dificuldades lingüísticas específicas dos alunos por meio de tarefas ou exercícios lingüísticos especialmente elaborados. Encontramos também estudos (Lyster e Ranta, 1997; Panova e Lyster, 2002; Lima, 2002; Menti, 2003, entre outros) que analisam, do ponto de vista interacional, o tratamento dado a determinados erros lingüísticos produzidos pelos alunos.

* Professoras da Universidade Federal do Rio Grande do Sul.

1 SPADA, N. Form-focused instruction and second language acquisition: A review of classroom and laboratory research. Language Teaching, n. 29, 1997, p.1. 
As reações corretivas na sala de aula constituem o que denominamos aqui de tratamento corretivo ou feedback corretivo. O termo negociação da forma (Lyster e Ranta, 1997) reflete os modos como os professores focalizam a forma durante as interações com os alunos em salas de aula comunicativas. A negociação da forma implica uma função didática, ou seja, a de proporcionar feedback corretivo que encoraja o aluno a procurar recursos para corrigir o próprio erro, buscando uma produção (e não apenas compreensão) mais precisa. ${ }^{2}$ Em nossa discussão, estaremos tratando de estudos nos quais erros de forma referem-se a erros gramaticais, lexicais e fonológicos, conforme Lyster e Ranta (1997).

Destacaremos aqui alguns dos estudos que elegemos como os mais relevantes para nossa discussão e, especialmente, para a pesquisa que temos desenvolvido junto ao Projeto Alesa (Aquisição de Língua Estrangeira em Sala de Aula) ${ }^{3}$. Entretanto, antes de tratarmos dos estudos específicos, será esclarecedor mencionar alguns aspectos teóricos fundamentais para a compreensão do assunto, o que nos remete a considerações sobre o ensino comunicativo de línguas.

\section{O ensino comunicativo de línguas e a instrução com foco na forma}

O ensino de línguas tem sido marcado por várias mudanças teóricas e diferentes abordagens. Spada (2004) apresenta uma abrangente revisão das influências teóricas e de pesquisa sobre o ensino comunicativo de línguas (ECL). A teoria da competência comunicativa de Hymes (1972) não poderia deixar de ser mencionada por enfatizar a noção de que saber uma língua inclui não apenas a competência lingüística (o conhecimento de regras gramaticais), mas também a competência comunicativa (conhecimento de regras de uso da língua). Hymes ampliou a noção de competência e gerou discussões que provocaram questões cruciais sobre o status da precisão gramatical. Em sua revisão, Spada (2004) destaca as diferentes concepções de estudiosos (pesquisadores e professores) interessados em aquisição e ensino de L2, observando que a tendência dos lingüistas aplicados

2 LYSTER, R.: RANTA, L. Corrective feedback and learner uptake: Negotiation of form in communicative classrooms. Studies in Second Language Acquisition, n. 19, 1997, p. 42.

3 O Projeto ALESAé desenvolvido junto ao PPG-Letras da Universidade Federal do Rio Grande do Sul . 
britânicos foi a de incorporar significado e forma, enquanto que na América do Norte houve divergência de opiniões a respeito de como a abordagem comunicativa de línguas deve ser vista, havendo uma tendência de se considerar a centralidade do significado (ou sentido).

No Brasil, o ECL tem tido várias faces e interpretações. Embora seja entendido por muitos, teoricamente, como uma abordagem que deve focalizar o sentido e não a forma, na prática há uma grande variedade de comportamentos na sala de aula, onde temos observado, em algumas instâncias, o predomínio do foco nas formas (Long e Robinson, 1998)4, ou seja, nos conteúdos gramaticais. Em outras instâncias, observa-se também uma centralização no sentido e, em outras, uma combinação de foco no sentido e foco na forma.

Wesche e Skehan (2002) estabelecem distinção entre uma versão forte e outra fraca do ECL, com base em Howatt (1984). Embora essas versões compartilhem os mesmos objetivos, ou seja, a aprendizagem da língua-alvo, elas refletem diferentes orientações sobre como se aprende uma L2/LE.

Os defensores da versão forte crêem que o engajamento no uso comunicativo da língua, prevalecendo o foco no sentido, é o caminho para a aprendizagem e um syllabus natural irá emergir através das interações. Ou seja, comunicação é a chave, formas lingüísticas não devem ser enfatizadas e correção de erros deve ser evitada. Exemplos da aplicabilidade dessa versão são os programas de imersão, alguns programas de instrução com foco em tarefas e instrução com foco no conteúdo. Já na versão fraca, a comunicação espontânea é vista como um fim e não um meio único e incorpora práticas baseadas na descrição de traços comunicativos da língua, tais como formas adequadas para expressar funções linguísticas. O ponto de vista que aqui defendemos adota a versão fraca do ECL, que acreditamos ser mais eficiente nas instâncias de ensino e aprendizagem de língua estrangeira propriamente dita.

No Canadá, vários estudos que analisaram os programas de imersão francesa (Harley e Swain, 1978; Hammerly, 1987; Harley, 1993, entre outros), nos quais os professores dão aos aprendizes uma grande quantidade e variedade de insumo compreensível, evidenciaram que a provisão de uma ampla quantidade de insumo não é suficiente para o aprendiz de L2 atingir um alto nível de proficiência na língua. Embora demonstrassem boa compreensão oral e auditiva e alguma fluência nas habilidades oral e escrita, os alunos apresentavam problemas de precisão

4 LONG, M.; ROBINSON, P. Focus on form: Theory, research and practice. In C. Doughty e J. Williams (Eds.). Focus on form in classroom second language acquisition. Cambridge: Cambridge University Press, 1998, p. 16. Grifo dos autores. 
lingüística. Foi, então, que Swain (1985) enfatizou a importância da produção forçada (pushed output). Conforme a autora, ao serem forçados a produzir a língua de modo a serem compreendidos por seu interlocutor, os aprendizes terão condições de perceber seus erros e tornar sua interlíngua (a língua do aprendiz) mais precisa. A partir desta afirmação, adotamos aqui o termo output como significando a produção oral ou escrita do aprendiz de língua.

Swain (1995) amplia o escopo da hipótese que havia apresentado anteriormente (Swain, 1985) ao discutir três funções que o output tem no processo: (1) a função da percepção, considerando que, ao produzir a língua-alvo, o aprendiz tem a oportunidade de perceber uma lacuna entre o que ele quer dizer e o que consegue produzir de fato, o que pode ajudá-lo a perceber o que não sabe; (2) a função de testagem de hipóteses, considerando-se que produzir a fala é, potencialmente, um modo de o aprendiz testar suas hipóteses sobre a língua-alvo; ele testa a compreensibilidade e a correta formação lingüística de sua interlíngua a partir do feedback obtido de seus interlocutores; e (3) a função metalinguiística (metafala), pois a reflexão sobre o uso da língua-alvo pode capacitar o aluno a controlar e internalizar o conhecimento lingüístico, contribuindo para a sua conscientização quanto às regras e formas lingüísticas e às relações entre elas. Desse modo, os alunos perceberão problemas em sua interlíngua a partir de seu feedback interno e/ou de feedback externo obtido dos interlocutores na troca interativa.

Em suma, o ponto de vista teórico que subjaz aos estudos que defendem a instrução com foco na forma no ECL é que apenas o insumo compreensível, nos termos de Krashen (1981), não é suficiente para a aprendizagem de uma língua (Schmidt e Frota,1986). Os aprendizes precisam de evidência negativa, isto é, informação sobre a não gramaticalidade de seus enunciados, pois apenas exposição à língua não é suficiente. Ao produzir a LE, durante a interação com o professor e os colegas, os aprendizes podem reconhecer alguns de seus próprios problemas lingüísticos e isso pode ajudá-los a descobrir o que precisam aprender sobre a línguaalvo. Esse comportamento pode estimular processos cognitivos, que gerarão novo conhecimento lingüístico, ou consolidarão o conhecimento que eles já possuem (Swain e Lapkin, 1994).

Wesche e Skehan (2002) ${ }^{5}$ afirmam que a pesquisa em vários contextos do ECL sugere que a IFF é mais eficaz quando diretamente relacionada à comunicação significativa, seja por meio da manipulação de materiais e tarefas para salientar

5 WESCHE, M. B.; SKEHAN, P. Communicative, task-based, and content-based language instruction. In: KAPLAN, R. B. (Ed.). The Oxford Handbook of Applied Linguistics. Oxford: Oxford University Press, 2002, p. 211. 
determinados traços lingüísticos, feedback comunicativo ao aluno, prática de certos componentes, ênfase na produção planejada ou explicação quando surgem problemas de comunicação.

\section{Estudos sobre o tratamento corretivo da forma}

Alguns estudos observacionais mostraram-se particularmente relevantes quanto a seus resultados referentes ao comportamento dos professores e alunos como interagentes na instância da sala de aula. Dois estudos canadenses destacam-se: Lyster e Ranta (1997) e Panova e Lyster (2002), ambos apresentando dados gravados em áudio. O estudo de Lyster e Ranta, usado como modelo analítico em algumas pesquisas, descreve o comportamento corretivo em salas de aula de francês em contexto de imersão no Canadá, com alunos com idades entre 9 e 11 anos. Trata-se de um estudo descritivo para o qual os autores apresentam um modelo interacional para analisar como se dá o feedback corretivo e a negociação da forma na sala de aula.

Lyster e Ranta observaram os diferentes tipos de feedback corretivo utilizados pelos professores, a frequiência de cada tipo de feedback utilizado e quanto uptake (resposta ou reação do aluno imediatamente após ao feedback do professor) cada tipo de feedback gera. Foram encontrados seis tipos de feedback corretivo: correção explícita; recast; pedido de esclarecimento; feedback metalingüístico; elicitação e repetição corretiva, definidos e ilustrados a seguir.

Lyster e Ranta definem correção explícita como feedback no qual o professor fornece a forma correta e claramente indica que a produção estava incorreta, como no exemplo (1). ${ }^{6}$

(1) Professora: Would you have had some ice cream if I had asked you?

Jana: I will.

Professora: You would. You should say "I would".

Jana: Yes, okay.

Recasts são definidos como movimentos corretivos quando o professor reformula todo ou parte do enunciado do aluno.

6 Todos os exemplos aqui apresentados para ilustrar os tipos de feedback corretivo foram retirados de Lima (2002) e se constituem em dados de Projeto Pós-Doutoral desenvolvido na Universidade de Toronto, Canadá, com Bolsa Capes, junto à equipe da Profa. Dra. Nina Spada, no período de agosto de 2001 a julho de 2002, focalizando uma sala de aula de inglês em contexto brasileiro. Esse estudo é parte do Projeto ALESA - Aquisição de LE em Sala de Aula - do PPG-Letras da UFRGS. 
(2) Marco: Who see his card?

Professora: Who saw his card? (sem ênfase à forma verbal)

Pedidos de esclarecimento constituem o tipo de feedback corretivo no qual o professor expressa que não compreendeu o enunciado do aluno e espera que ele responda.

(3) Bela: That was when the Portuguese realized that the Indians are sick.

Professora: Uh hum. What do you mean by "are sick"?

Bela: They become became sick with the diseases the Portuguese brought.

Feedback metalingüístico é um movimento corretivo no qual o professor fornece informações ou perguntas relacionadas à formação correta do enunciado do aluno, mas não provê a forma correta diretamente.

(4) Marco: They can preserve her cultural things.

Professora: No, "her" is not correct. It's not third person singular.

Marco: Their they they their cultural things but they have to use our things.

Elicitação é entendido como feedback quando o professor solicita diretamente a reformulação do enunciado ao aluno.

(5) Marco: The Europeans wanted our rocks our precious rocks.

Professora: They wanted our precious ......

Jana: Our caves.

Professora: Something similar to a rock. There is a famous band that sings rock and roll, it's called Rolling.....

Marco: Oh, yes. Rolling Stones. Precious stones.

Repetição corretiva é feedback corretivo no qual o professor repete o enunciado mal formulado pelo aluno, dando ênfase ao erro por meio da entonação, mas não provê a forma correta.

(6) Paula: The govern say everything is okay.

Professora: The govern?

Paula: Oh, the government.

Lyster e Ranta constataram a predominância de comportamentos corretivos (especialmente recasts) que não oportunizam ao aprendiz a correção do próprio erro $^{7}$. É primordial observar que nesse e em outros estudos, por exemplo Panova e Lyster (2002) e Lima (2002), resumidos abaixo, houve uma tendência de os professores optarem por técnicas corretivas mais reformuladoras (recasts e correção explícita) do erro do aprendiz do que elicitativas (pedido de esclarecimento, feedback metalingüístico, elicitação e repetição corretiva).

7 No entanto, ao leitor interessado nesse tópico indicamos o artigo de Nicholas, Lightbown e Spada (2001) para uma ampliação das definições de recasts em outras instâncias. 
O estudo de autoria de Panova e Lyster (2002) relata resultados muito semelhantes, embora num contexto diferente de sala de aula. A investigação foi realizada com aprendizes adultos de inglês, em Montreal, seguindo o modelo de Lyster e Ranta. Foram analisadas 6 horas de gravação em uma classe de 25 alunos, sendo francês a língua comum a todos. Os resultados demonstraram novamente uma forte preferência pelo uso de recasts por parte da professora, reduzindo a chance de os alunos gerarem suas próprias correções.

No contexto brasileiro, utilizando-se do mesmo modelo analítico, Lima (2002) investigou o comportamento corretivo de uma professora e as reações dos aprendizes numa sala de aula comunicativa de inglês como LE no sul do Brasil. Foram analisadas 6 horas de interação gravadas em vídeo e áudio em uma sala de aula de aprendizes de nível pré-intermediário em uma escola particular de ensino de línguas. Os alunos eram quatro adolescentes com idades entre 14 e 16 anos. Assim como em Panova e Lyster e em outros estudos, os resultados indicaram uma preferência da professora brasileira pelo uso de técnicas corretivas mais reformuladoras do erro do aprendiz do que elicitativas. Embora desenvolvidos em ambientes instrucionais diferentes, os três estudos mostram a tendência do professor de empregar tipos reformulativos de movimentos de feedback que não permitem aos aprendizes terem um papel ativo na correção dos próprios erros ou negociá-los com os colegas, ou seja, a negociação da forma não é estimulada.

Embora o modelo de Lyster e Ranta pareça dar conta dos principais movimentos corretivos da sala de aula, algumas restrições podem ser feitas a ele. Uma delas se refere ao conceito de uptake, que significa qualquer reação observável do aprendiz ao tratamento corretivo que evidencie que ele percebeu que houve correção ao seu enunciado. Essas reações do aprendiz podem incluir não apenas o auto-reparo propriamente dito, mas também (ou somente) gestos (por exemplo, sacudir a cabeça em concordância) ou manifestações verbais, tais como 'uh hum', 'okay', 'right', além da produção de outros enunciados. No entanto, faz-se necessário notar que, na verdade, as manifestações gestuais e verbais classificadas como uptake nem sempre devem ser entendidas pelo pesquisador como manifestações de que o aluno percebeu a correção. Essa é uma importante crítica ao modelo de Lyster e Ranta, pois entendemos como absolutamente primordial utilizar procedimentos para que isso seja verificado de fato, tais como entrevistar os alunos ou elicitar protocolos em voz alta em sessões de visionamento, para sabermos se ele realmente percebeu a correção ou não (Lima, 2002).

Lima (2002) constatou ainda que recasts, na sala de aula brasileira, geraram mais uptake do que nos outros dois estudos mencionados acima. Ela atribui essa diferença ao número pequeno de alunos em aula, o que possibilitou mais e melhor 
interação entre os alunos com o professor e com seus colegas, e ao nível mais proficiente dos alunos, explicando que esses alunos provavelmente perceberam os movimentos corretivos do professor com maior freqüência do que nos outros estudos, dado o maior domínio da língua-alvo e proximidade com o professor. Também explica que o professor produziu recast com e sem ênfase ao erro e que recast com ênfase (entonação marcando o erro e movimento facial) gerou mais uptake, distinção que não tinha sido feita por Lyster e Ranta. Essa distinção de recasts com e sem ênfase, como categorias analíticas distintas, já havia sido referida por Chaudron (1977) e não é feita nas análises de Lyster e Ranta (1997) e de Panova e Lyster (2002), mas é indispensável que se faça, pois nem todos os recasts em sala de aula podem ser considerados neutros (Nicholas, Lightbown e Spada, 2001). Lima também confirma em seu estudo que elicitação é um dos tipos de feedback corretivo que mais gera uptake, embora a freqüência desse movimento corretivo não tenha sido alta.

Os três estudos observacionais brevemente discutidos anteriormente focalizam a interação na sala de aula a partir do comportamento do professor. Não são muitas as pesquisas encontradas na literatura especializada que têm o aluno como centro do processo de tratamento do erro. Ohta (2000), Ellis, Basturkmen e Loewen (2001) e Menti (2003) são alguns desses estudos.

A falta de uma reação verbal por parte do aluno corrigido pelo professor tem sido entendida como um sinal da ineficiência do feedback corretivo. Alguns pesquisadores questionam essa afirmação. Entre eles, destaca-se Ohta (2000), que investiga como os aprendizes reagem aos recasts na sala de aula de LE no Japão. Um dos objetivos dessa pesquisa é determinar que procedimentos podem ser mais bem sucedidos em auxiliar o aprendiz a aumentar a acurácia da sua produção. Ohta reconsidera a saliência e a eficácia potencial dos recasts, focalizando a análise da fala particular ('private speech') de aprendizes de japonês como LE. Ela analisou as reações verbais, incluindo perguntas que o próprio aprendiz se faz, e que servem de janela para as atividades mentais do aprendiz. Esses dados revelam que o aprendiz está mentalmente ativo ao responder ou analisar recasts, considerando que a fala particular revela atividade mental.

Ohta enfatiza que os processos cognitivos são de origem social, com realidades de interação social que formam estruturas de cognição. A fala particular surge por meio de processos sociocognitivos da aprendizagem da língua e quando uma criança aprende a falar, a língua está inserida numa interação social. A fala particular faz parte do processo de internalização, sendo por si só uma forma transicional entre a fala social e a interior (Vygotsky, 1987). Segundo a autora, para os adultos, a fala particular serve como uma ferramenta cognitiva na aprendizagem de uma língua e como um mecanismo de testagem de hipóteses para tentar resolver 
problemas da língua-alvo. Seu estudo focaliza o que dados de fala particular podem revelar sobre a saliência dos recasts para os aprendizes e o processo de feedback corretivo em sala de aula de LE. A autora investigou: (a) a saliência de contrastes apresentada nos recasts, (b) o impacto dos recasts sobre outros membros da sala de aula que não são aqueles a quem ofeedback é dirigido e (c) se e como os aprendizes são capazes de usar enunciados que contrastem com seus próprios enunciados mal formulados.

Os participantes foram sete estudantes universitários observados durante o ano acadêmico. As aulas foram gravadas em vídeo e áudio e os alunos foram expostos a diferentes professores durante $\mathrm{o}$ ano. As produções em áudio foram gravadas por meio de pequenos gravadores e microfones presos às roupas dos estudantes. Cópias do material usado em aula foram recolhidas para análise. Foram gravadas 34 horas de instrução em sala de aula, sendo as transcrições feitas pela pesquisadora e assistentes usando a metodologia da análise da conversa. Os professores davam as instruções em japonês e o foco na forma foi bastante trabalhado nas atividades de ensino, com aulas de gramática explícita uma vez por semana, e atividades instrucionais e tarefas de aprendizagem em grupo desenvolvidas para atingir certas estruturas gramaticais e vocabulário.

Considerando a relação entre fala particular e feedback corretivo, os aprendizes foram considerados participantes conversacionais não apenas quando o feedback corretivo era dirigido a eles, mas também quando estavam no papel de auditores, isto é, pessoas a quem o feedback não foi dirigido, mas cuja participação no grupo é permitida e eles podem se tornar destinatários do feedback. Ohta observa que os aprendizes produziram mais fala particular quando não eram destinatários, mas sim auditores. A fala particular também foi bastante freqüente quando o professor se dirigia à turma como um todo. Recasts incidentais funcionam como reformulações da perspectiva do aprendiz, não importando se deveriam ter sido entendidas como corretivas por aqueles que as emitiram, e mesmo que não sejam endereçadas individualmente ao aprendiz.

Os dados evidenciam a saliência dos recasts a partir das respostas dos auditores às reformulações que foram endereçadas a outros indivíduos. Os alunos reagiram aos enunciados contrastantes que ocorreram incidentalmente quando responderam a enunciados emitidos pelo professor e dirigidos a toda a turma ou a outro colega, evidenciando que os recasts são salientes e úteis para aprendizes de língua.

Estudos anteriores acreditavam que o envolvimento ativo podia ser medido apenas pelas respostas orais do aprendiz a quem o feedback corretivo se destinava. No entanto, a análise aqui resumida aponta para o fato de que a coleta de dados 
centrada no professor deixa passar grande parte da interação em sala de aula. Segundo a pesquisa de Ohta, a fala particular é fundamental para o entendimento do processo de aquisição de uma língua. Pesquisa sobre feedback corretivo centrada no aprendiz é recente e é preciso levar em consideração outros fatores, tais como nível de proficiência e interesses individuais.

Ellis, Basturkmen e Loewen (2001) também investigaram o uptake de alunos adultos aprendendo inglês como L2. As reações dos aprendizes foram estudadas em episódios de foco na forma durante 12 horas de ensino comunicativo em dois grupos de alunos matriculados numa escola particular de línguas na Nova Zelândia. Os autores definiram uptake sob uma perspectiva mais ampla, considerando que o uptake pode ocorrer mesmo quando o movimento discursivo anterior ao uptake não incluir feedback corretivo. Explicam tal decisão dizendo que há ocasiões nas aulas comunicativas nas quais os próprios aprendizes chamam a atenção para uma forma lingüística, elicitando, desse modo, não um movimento corretivo do professor, mas um movimento reativo do professor. Isso se caracteriza como um foco na forma iniciado pelo aprendiz e os aprendizes ainda têm a oportunidade de reagir tentando utilizar a forma focalizada na sua produção. Nesse sentido, o uptake é um movimento do aluno, é opcional, ocorre em episódios nos quais os aprendizes tenham demonstrado uma lacuna em seu conhecimento (por exemplo, cometendo um erro ou fazendo uma pergunta) e o uptake acontece como uma reação a um movimento discursivo anterior no qual um outro participante (geralmente o professor) provê informação sobre um item lingüístico de modo implícito ou explícito.

Como em outros estudos, os recasts (definidos conforme Lyster e Ranta, 1997) também predominaram neste contexto. Segundo os autores, isso parece refletir a preocupação dos professores em manter a fluência dos alunos. Eles mostraram-se surpreendidos pelo fato de que a ocorrência de pedidos de esclarecimento como movimento corretivo foi praticamente ausente, o que deve ter sido ocasionado pelo nível de controle que os professores impuseram ao discurso. Em outras palavras, recasts mantêm a correção sob o domínio do professor, enquanto que pedidos de esclarecimento a transferem para o aprendiz. A grande maioria dos episódios de negociação observados envolveu negociação da forma em oposição à negociação de sentido. A atenção à forma nessas aulas refletiu uma grande preocupação com o código mais do que com o sentido. Entretanto, é preciso notar que as formas tratadas surgiram no contexto de tarefas comunicativas. Por outro lado, o uptake dos aprendizes foi mais freqüente em episódios envolvendo negociação de sentido, mas foram episódios que focalizaram dificuldades com o léxico. Os autores observaram também que o uptake foi muito mais freqüente e eficaz quando as seqüências foram iniciadas pelos próprios alunos. 
Uma interessante observação dos autores tem a ver com o fato de que, segundo eles, os resultados mostraram que o uptake dos alunos foi muito mais freqüente e mais bem sucedido do que os resultados de estudos em grupos de imersão canadense como o de Lyster e Ranta (1997), especialmente quanto às reações aos recasts, pois, no estudo de Ellis, Basturkmen e Loewen, os recasts foram seguidos de uptake bem sucedido numa freqüência relativamente mais alta. Os autores especulam sobre as possíveis razões para essa diferença: Lyster e Ranta examinaram o comportamento de crianças de escola regular do sistema de ensino canadense, enquanto que o estudo deles focalizou adultos e pagantes, compromissados com a própria aprendizagem. Eles acham razoável considerar que esses adultos, além de serem mais cognitivamente capazes, estavam mais motivados a prestar atenção à forma do que as crianças no estudo de Lyster e Ranta.

Ellis, Basturkmen e Loewen concluem que o procedimento comum aos professores de fazer perguntas aos alunos sobre as formas que eles (professores) consideram problemáticas pode não ser muito eficaz se considerarmos o uptake como uma medida de eficácia. Por outro lado, encorajar o aprendiz a fazer suas próprias perguntas sobre forma é um procedimento muito mais eficaz. $\mathrm{O}$ estudo também mostra, contrariamente ao que foi afirmado por Lyster e Ranta, que recasts podem ser bem sucedidos no sentido de provocar reação dos alunos e se forem usados por aprendizes motivados e compromissados com a própria aprendizagem.

Outro estudo que trata da reação do aprendiz ao tratamento corretivo e das possíveis relações com a aprendizagem da língua-alvo, desta feita no contexto brasileiro, é o de Menti (2003). Desenvolvendo pesquisa no âmbito do Projeto ALESA, Menti investigou a influência de dois tipos de feedback corretivo, recast sem ênfase e elicitação, no desempenho de alunos de duas turmas de nível intermediário de inglês como LE em um curso particular de idiomas que segue os princípios da abordagem comunicativa. Esse tipo de pesquisa é importante no sentido de explorar como os diferentes tipos de feedback corretivo afetam a aquisição de LE.

A escolha de recast e elicitação como foco desse estudo se deve principalmente a dois fatores. Primeiramente, esses dois tipos de feedback corretivo são empregados de fato por professores de línguas. Segundo, do ponto de vista da reação do aprendiz, esses dois movimentos apresentam diferenças fundamentais, principalmente no que concerne ao uptake e ao auto-reparo, o que gera diferentes implicações para a aprendizagem, conforme já sugerimos. Elicitação exige uptake e auto-reparo por parte do aluno, já que é um tipo de feedback que pede para o aluno reformular seu enunciado, enquanto que recasts, especialmente aqueles sem ênfase empregados nesse estudo, não exigem esse comportamento do aluno, uma vez que o próprio professor reformula corretamente o enunciado. Uma outra diferença 
entre esses dois tipos de feedback é que enquanto não há dúvida de que elicitação serve como evidência negativa, há muito debate em torno da questão se recasts fornecem evidência positiva ou negativa ao aluno (Nicholas, Lightbown e Spada, 2001).

Tipos de feedback corretivo que geram output em forma de reformulação de enunciados por parte dos alunos (uptake) são apontados como mais benéficos à aprendizagem. Como vimos, elicitação é um tipo de feedback que se enquadra nessa descrição.

Os dados obtidos na investigação de Menti foram analisados qualitativa e quantitativamente, almejando retratar como o uso de diferentes tipos de feedback corretivo pode influenciar a aquisição de LE, considerando-se a relevância de se observar o erro em interação. Os participantes eram alunos de duas turmas de inglês de um curso particular de línguas, que prioriza o uso da LE para comunicação em situações autênticas do uso de linguagem, sendo uma escola que trabalha com foco na forma - explica estruturas de modo explícito e implícito e promove feedback corretivo em um contexto comunicativo. Cada turma tinha 5 alunos adolescentes, tendo em média 16 anos. As duas turmas iniciaram seus estudos da LE na mesma escola e seus integrantes estavam juntos na mesma turma há mais de três semestres. Os alunos não foram informados a respeito do tipo de pesquisa realizada nem seu objetivo, tendo sido apenas convidados a participar de um estudo que estava sendo realizado na escola. Eles concordaram com a gravação de 4 tarefas e a gravação de 3 encontros com a pesquisadora de 15 minutos de duração cada - tempo no qual os pré-testes, pós-testes e testes postergados foram feitos. Os alunos das duas turmas estavam habituados a realizar tarefas semelhantes às propostas e a ter uma câmera de vídeo presente na sala de aula. Em geral, gostavam de atividades comunicativas e gostavam de falar em inglês em aula.

As características do nível intermediário são ideais para estudar foco na forma através de feedback corretivo, pois os alunos já possuem conhecimento sobre as estruturas básicas e já receberam informação sobre o funcionamento das mesmas. Os alunos participantes já conheciam praticamente todas as estruturas básicas da língua inglesa, geralmente conhecendo as regras e informações sobre o funcionamento e uso dessas estruturas, mas ainda cometiam erros ao usá-las corretamente em situações autênticas e comunicativas.

Os próprios professores das duas turmas participaram do experimento e da escolha da estrutura em foco, que era o uso de perguntas no passado. Ambos estavam cientes de todas as etapas do estudo, conhecendo seus objetivos e seu formato. Eles escolheram a forma de feedback corretivo (elicitação ou recast) que usariam para corrigir os erros dos seus alunos durante as tarefas de acordo com suas preferências. Do ponto de vista operacional, então, cada professor deveria corrigir seus alunos 
usando primordialmente o movimento corretivo escolhido.

Três testes foram elaborados para verificar o desempenho dos alunos antes da intervenção (pré-teste), logo após a intervenção (pós-teste) e, após duas semanas da última intervenção, o último teste (teste postergado). Mackey e Philp (1998), Doughty e Varela (1998), Spada e Lightbown $(1993,1999)$ também adotaram prétestes, pós-testes e testes postergados em seus estudos. Os testes foram de julgamento de gramaticalidade, exercício direcionado e exercício livre. Spada e Lightbown $(1993,1999)$ usaram instrumentos similares; os mesmos intervalos de tempo utilizados por elas foram mantidos no estudo. As tarefas usadas para provocar o uso da estrutura em foco foram desenhadas para se assemelharem às tarefas geralmente propostas pelos professores participantes do estudo.

O objetivo da análise dos dados foi o de verificar se houve diferença no desempenho de cada aluno após a intervenção realizada durante as tarefas institucionais. Também foi possível analisar os dados de cada grupo como um todo, uma vez que os dois grupos tiveram comportamentos bem distintos. Embora o número reduzido de participantes impossibilite qualquer generalização sobre a vantagem do uso de um tipo de feedback corretivo sobre o outro, Menti observou desempenho e progresso de cada aluno participante individualmente e traçou as tendências de cada grupo.

Quanto aos resultados, os alunos que receberam elicitação como feedback corretivo tiveram desempenho melhor nos pós-testes e nos testes postergados no exercício direcionado. Essa diferença de desempenho entre os dois grupos pode ser atribuída ao tipo de feedback corretivo que receberam. São dois grupos do mesmo nível de proficiência que receberam as mesmas tarefas, os mesmos testes, o mesmo tempo para realizá-los, e fizeram os testes nos mesmos dias. A principal diferença de comportamento entre os dois professores foi o tipo de feedback corretivo utilizado. Outra importante diferença foi o quanto cada professor interveio e o quanto focalizou as intervenções na estrutura em foco. O professor do grupo de elicitação interveio com mais frequiência e também focalizou mais suas intervenções na estrutura em foco do que o professor do grupo de recasts. Essa diferença deve ter exercido influência nos resultados, pois gerou mais atenção por parte do aluno à estrutura focalizada, observação que encontra suporte também em Williams e Evans (1998).

Os resultados obtidos nessa investigação sugerem a confirmação de sua hipótese norteadora, ou seja, que feedback corretivo fornecido ao aluno em forma de elicitação é mais eficaz, ou influi de maneira mais positiva, no desempenho de aprendizes do que feedback corretivo fornecido por meio de recast, o que se explica pela natureza distinta dos dois comportamentos corretivos. 


\section{Conclusões}

São várias as questões e implicações que podem ser apontadas envolvendo todas as variáveis contidas nos estudos aqui discutidos. Entretanto, este espaço não permite que nos alonguemos. Antes de concluirmos, é importante frisar que todos os movimentos corretivos têm uma função sóciointerativa na sala de aula. Embora o feedback corretivo na aula comunicativa possa oferecer muitas ocasiões para a negociação da forma, como vimos, há evidências de que o tratamento do erro fornecido pelos professores de língua nem sempre estimula os aprendizes a focalizar seu output e , assim, são negligenciadas oportunidades para que eles possam refletir sobre a língua que produzem, corrigir seus próprios erros e negociar a correção dos mesmos com seus colegas e com os professores.

Evidências dos motivos que levam os professores a optar em pelos diferentes modos de correção merecem o desenvolvimento de pesquisa detalhada ${ }^{8}$, considerando-se as muitas variáveis que devem estar envolvidas nessas decisões, tais como crenças de professores e alunos, idade, contexto social, estilos de aprendizagem, nível de proficiência e personalidades, entre outras. $\mathrm{O}$ uso frequiente de recasts em diferentes contextos de sala de aula deve ser devido ao fato de esses movimentos corretivos serem menos intrusivos e agressivos, pois podem prover feedback de modo mais sutil, especialmente quando forem neutros, isto é, sem ênfase.

Os estudos sobre o uptake como manifestação de percepção de correção por parte dos aprendizes apontam para a importância de se considerar diferenças individuais e contextuais. Há sérias razões para crer que os aprendizes necessitam de evidência negativa, isto é, necessitam de informação que demonstre que suas hipóteses sobre a língua-alvo são errôneas. Essa constatação é especialmente relevante em contextos de língua estrangeira propriamente dita, no qual sabemos que oportunidades de exposição à língua-alvo são muito limitadas (Lima 2004). Tipos diferentes de feedback parecem ter efeitos distintos sobre a aprendizagem, da mesma forma que diferentes tipos de correção exigem graus variados de atenção. No entanto, é preciso que se diga que uptake bem-sucedido não é garantia de aprendizagem e mais pesquisas são necessárias para estabelecer essa e outras relações entre tratamento corretivo, uptake e aprendizagem.

8 Um exemplo é o estudo de FREUDENBERGER, F.; LIMA. M. D. S. Relacionando tratamento do erro e crenças na aula de língua estrangeira: um estudo de caso. Revista Formas e Linguagens, Ijuí: Unijuí,. v. 6, p. 42-53, 2003. 
Finalmente, por ser um evento interacional, o tratamento corretivo é importante para o desenvolvimento da autonomia do aprendiz, o que, em última análise, é o que todos nós, professores de LE e formadores de professores de LE, almejamos (Lima, 2004). O desenvolvimento da autonomia de nossos aprendizes é muito influenciado pelo modo como nós, professores de língua e educadores, organizamos a prática do ensino e da aprendizagem. Essa prática implica provimento de feedback corretivo que auxilie o aprendiz a ter um papel ativo no seu processo de aprendizagem.

\title{
RESUMO
}

Neste artigo tratamos de algumas questões cruciais de ensino e aprendizagem de segunda língua (L2) e língua estrangeira (LE) relativas ao tratamento corretivo da forma na sala de aula. Primeiramente, revisamos a relação entre a instrução com foco na forma e o ensino comunicativo de línguas e apresentamos alguns conceitos essenciais. Em segundo lugar, discutimos alguns estudos encontrados na literatura especializada (Lyster e Ranta, 1997; Panova e Lyster, 2002; Ohta, 2000 e Ellis, Basturkmen e Loewen, 2001), destacando dois estudos no contexto brasileiro (Lima, 2002; Menti, 2003). Finalmente, apresentamos nossas conclusões e implicações sobre as principais questões levantadas. Palavras-chave: Tratamento corretivo, negociação da forma, língua estrangeira.

\begin{abstract}
This article deals with some fundamental issues in teaching and learning a second and foreign language pertaining to corrective treatment of form in the classroom. We will first review the relation between focus on form teaching and communicative language teaching and will present some essential concepts related to these two approaches. We will then discuss some studies available in the specialized literature (Lyster and Ranta, 1997; Panova and Lyster, 2002; Ohta, 2000 and Ellis, Basturkmen and Loewen 2001), giving special attention to two studies carried out in the Brazilian context (Lima, 2002; Menti, 2003). We will close by presenting our conclusions and implications of the main issues discussed.
\end{abstract}

Key-words: Corrective feedback, negotiation of form, foreign language. 


\section{REFERÊNCIAS}

CAROLL, S.; SWAIN, M. Explicit and implicit negative feedback: An empirical study of the learning of linguistic generalizations. Studies in Second Language Acquisition, n. 15, p. 357-386, 1993.

CHAUDRON, C. A descriptive model of discourse in the corrective treatment of learners' errors. Language Learning, n 27, p. 29-46, 1977.

DOUGHTY, C; VARELA, E. Communicative focus on form. In: DOUGHTY, C.; WILLIAMS, J. (Eds.). Focus on form in classroom SLA. Cambridge: Cambridge University Press, p.114-138, 1998.

ELLIS, R.; BASTURKMEN, H.; LOEWEN, S. Learner uptake in communicative ESL lessons. Language Learning 51: Supplement 1. Form-Focussed Instruction and Second Language Learning, p.281-318, 2001.

FREUDENBERGER, F.; LIMA. M. D. S. Relacionando tratamento do erro e crenças na aula de língua estrangeira: um estudo de caso. Revista Formas e Linguagens, Unijuí, v. 6, p. 42-53, 2003.

HAMMERLY, H. The immersion program: Litmus test of second language acquisition through language communication. The Modern Language Journal, n. 71, p.395-401, 1987.

HARLEY, B. Instructional strategies and SLA in early French immersion. Studies in Second Language Acquisition, n. 15, p. 245-260, 1993.

HARLEY, B.; SWAIN, M. An analysis of the verb system by young learners of French. Interlanguage Studies Bulletin, n. 3, p.35-79, 1978.

HYMES, D. On communicative competence. In: PRIDE, J. B.; HOLMES, J. (Eds.). Sociolinguistics: Selected Readings. Harmondsworth: Penguin, p. 269-293, 1972.

KRASHEN, S. Second language acquisition and second language learning. Oxford: Pergamon, 1981.

HOWATT, A. A history of English language teaching Oxford: Oxford University Press, 1984.

LIMA, M. D. S. A autonomia do aluno de língua estrangeira e a correção de seus erros. In: ROTTAVA, L.; LIMA, M. D. S. (Orgs.) Lingüística aplicada: relacionando teoria e prática no ensino de línguas. Ijuí: UNIJUÍ, 2004 (no prelo).

LIMA, M. D. S. Corrective feedback and interaction: the negotiation of form in a Brazilian EFL classroom. Paper presented at the Canadian Association of Applied Linguistics Conference, University of Toronto, May 2002.

LIMA, M. D. S. A autonomia do aluno de língua estrangeira e a correção de seus erros. In: ROTTAVA, L.; LIMA, M. D. S. (Org.). Lingüística aplicada: relacionando teoria e prática no ensino de línguas. Ijuí: Unijuí, 2004 (no prelo).

LYSTER, R.; RANTA, L. Corrective feedback and learner uptake: Negotiation of form in communicative classrooms. Studies in Second Language Acquisition, n. 19, p.37-66, 1997. 
LIMA, M. S. et al. O tratamento corretivo da forma no ensino e na...

LONG, M.; ROBINSON, P. Focus on form: Theory, research and practice. In: DOUGHTY, C.; WILLIAMS, J. (Eds.). Focus on form in classroom second language acquisition. Cambridge: Cambridge University Press, p. 15-63, 1998.

MACKEY, A.; PHILP, J. Conversation, interaction and second language development: recast, responses, and red herrings. Modern Language Journal, n. 82, 338-356, 1998.

MENTI, M. M. Efeito de dois tipos de feedback corretivo - recast e elicitação - no desempenho de alunos de inglês como língua estrangeira. Porto Alegre, 2003. Dissertação (Mestrado em Lingüística) - PPG-Letras da UFRGS.

NICHOLAS, H.; LIGHTBOWN, P. M.; SPADA, N. Recasts as feedback to language learners. Language Learning, v. 51, n. 4, p. 719-758, 2001.

OHTA, A. S. Rethinking recasts: a learner-centered examination of corrective feedback in the Japanese language classroom. In: HALL, J. K.; VERPLAETSE, L. S. Second and foreign language learning through classroom interaction. Mahwah, NJ: Lawrence Erlbaum, p.47-71, 2000.

PANOVA, I.; LYSTER, R. Patterns of corrective feedback and uptake in an adult ESL classroom. Tesol Quarterly, v. 36, n. 4, p.573-595, 2002.

SAMUDA, V. Guiding relationships between form and meaning during task performance: The role of the teacher. In: BYGATE; SKEHAN; SWAIN (Eds.). Researching pedagogic tasks: Second language learning, teaching, and testing. Harlow: Longman/Pearson Education, p. 119-140, 2001.

SCHMIDT, R.; FROTA, S. Developing basic conversational ability in a second language: A case study of an adult learner of Portuguese. In: DAY, R. (Ed.). Talking to learn. Rowley, MA: Newbury House, p. 237-326, 1986.

SPADA, N. Form-focused instruction and second language acquisition: A review of classroom and laboratory research. Language Teaching, n. 29, p. 1-15, 1997.

Coomunicative Language Teaching: Current status and future prospects. In: CUMMINS,

J.; DAVIDSON, C. (Eds.). Kluwer Handbook of English Language Teaching. Amsterdam: Kluwer Publications, 2004 (no prelo).

.; LIGHTBOWN, P.M. Instruction, L1 influence and developmental readiness in second language acquisition. Modern Language Journal, n. 83, p. 1-22, 1999.

SWAIN, M. Communicative competence: Some roles of SPADA, N. e LIGHTBOWN, P.M. Instruction and the development of questions in LE classrooms. Studies in Second Language Acquisition, n. 15, p. 205-224, 1993.

Communicative competence: Some roles of comprehensible input and comprehensible output in its development. In: GASS, S.; MADDEN, C. (Eds.). Input in second language acquisition. Rowley, MA: Newbury House, p. 235-253, 1985.

Three functions of output in second language learning. In: COOK, G.; SEIDLHOFER, B. (Eds.). Principles and practice in applied linguistics: Studies in honour of H. G. Widdowson. Oxford, UK: Oxford University Press, p.125-144, 1995.

.; LAPKIN, S. Problems in output and the cognitive processes they generate: A step towards second language learning. Applied Linguistics, n. 16, p. 370-391, 1994. 
LIMA, M. S. et al. O tratamento corretivo da forma no ensino e na...

VYGOTSKY, L. S. Mind in Society: The development of higher psychological processes. Cambridge, MA: Harvard University Press, 1987.

WESCHE, M. B.; SKEHAN, P. Communicative, task-based, and content-based language instruction. In: KAPLAN, R. B. (Ed.). The Oxford Handbook of Applied Linguistics. Oxford: Oxford University Press, p. 208-228, 2002.

WHITE, J. Getting learners's attention: A typographical input enhancement study. In: DOUGHTY, C.; WILLIAMS, J. (Eds.). Focus on forma in classroom second language acquisition. Cambridge: Cambridge University Press, p. 85-113, 1998.

WILLIAMS, J.; EVANS, J. What kind of focus and on which forms? In: DOUGHTY, C.; WILLIAMS, J. (Eds.). Focus on form in classroom second language acquisition. New York: Cambridge University Press, p. 139-155, 1998. 